\title{
Çimento Fabrikasında Gürültü Düzeylerinin Belirlenmesi
}

\author{
Özgür Kalelioğlu ${ }^{1 *}$, Ercan Köse ${ }^{2}$ \\ 1* Tarsus Üniversitesi, Lisansüstü Eğitim Enstitüsü, İş Sağlığı ve Güvenliği Anabilim Dalı, Mersin, Türkiye, (ORCID: 0000-0003-1545-9159), \\ ozgurkalelioglu@gmail.com \\ 2 Tarsus Üniversitesi, Mühendislik Fakültesi, Elektrik-Elektronik Mühendisliği Bölümü, Mersin, Türkiye (ORCID: 0000-0001-9814-6339), ercankos@,gmail.com
}

(İlk Geliş Tarihi 10 Mart 2021 ve Kabul Tarihi 30 Mayıs 2021)

(DOI: 10.31590/ejosat.893385)

ATIF/REFERENCE: Kalelioğlu, Ö. \& Köse, E. (2021). Çimento Fabrikasında Gürültü Düzeylerinin Belirlenmesi. Avrupa Bilim ve Teknoloji Dergisi, (25), 43-49.

\section{$\ddot{O} \mathbf{z}$}

Endüstrileşme ve modern anlamda teknolojilerin gelişmesi sonucunda meydana gelen sorunlardan birisi de ses kirliliğidir. Gürültü olarak da bilinen ses kirliliği, dinleyiciye anlamsız, istenmeyen gürültü ve insanları rahatsız eden düzensiz, yüksek ses olarak tanımlanır. Çalışma ve Sosyal Güvenlik Bakanlığı'na göre; Meslek hastalıklarının\% 10'u gürültüye bağlı işitme kaybı olarak tanımlanmaktadır. Yüksek gürültü seviyeleri canlıların yaşamına birçok yönden olumsuz etki etmektedir. İnsan sağlığı ile ilgili olumsuz sonuçların azaltılması veya yok edilmesi için gerekli tedbirlerin alınması gerekmektedir. Gürültünün etkilerini araştırmak üzere yapılan bu çalışmada işletmede TS 2607 ISO 1999:2005 ve TS EN ISO 11204 standartları kullanılarak gürültü düzeylerinin belirlenmesi ve çalışanlardaki etkilerinin ortaya konulması ile ilgili yapılan bu çalışmada 6 bölümde bulunan 11 ünitede toplam 33 gürültü maruziyet ölçümü ve bölümlerin yer aldığı noktalardan 6 adet ortam gürültü ölçümü gerçekleştirilmiştir. Yüksek gürültü düzeylerinin ölçüldüğü yerler için teknik ve çalışanlara yönelik tedbirler önerilmiştir.

Anahtar Kelimeler: İş Sağlı̆̆ı ve Güvenliği, Çimento, Gürültü.

\section{Determination of Noise Levels in Cement Factory}

\begin{abstract}
One of the problems that arise as a result of industrialization and the development of modern technologies is noise pollution. Sound pollution, also known as noise, is defined as meaningless, unwanted noise to the listener, and irregular, loud noises that disturb people. According to the Ministry of Labor and Social Security; 10\% of occupational diseases are defined as hearing loss due to noise. A total of 33 noise exposure measurements in 11 units in 6 departments and 6 from the points where the departments are located in this study, which was conducted to determine the noise levels using TS 2607 ISO 1999: 2005 and TS EN ISO 11204 standards and to reveal the effects on the employees in the plant producing cement. Ambient noise measurement was carried out. Technical and employee-oriented measures have been proposed for locations where high noise levels are measured.
\end{abstract}

Keywords: Occupational Health and Safety, Noise, Cement.

\footnotetext{
*Sorumlu Yazar: ozgurkalelioglu@gmail.com
} 


\section{Giriş}

Çimento sektörü, hammadde üreticisi konumu itibariyle inşaat ve yapım işlerini doğrudan besleyen bir sektördür. Ülkemiz Dünya çimento imalatında ilk 5'te yer almakta olup, son 10 yıllık süreçte üretim miktarını $\% 50$ arttırmış ve Avrupa'da sektörün lideri durumuna gelmiştir (Ünal, 2018). Üretimimiz yerel talebin tamamına cevap verebilmekteyken aynı zamanda sektörümüz Dünya ihracat sıralamasında da üst sıralarda yer almaktadır (Sönmez, 2018).

Endüstrileşme ve modern teknolojik gelişmeler ülkelere stratejik, ekonomik yönlerden olumlu değerler katmak ile birlikte, kuruldukları yerlerde ve çalışanlarında bazı olumsuzluklar oluşturmaktadırlar. Çimento sektöründe işçi sağlığı kapsamında yapılan tehlike tanımlama ve risk değerlendirme çalışmalarında kimyasal riskler, fiziksel riskler, çevresel riskler, enfeksiyon riskleri, akciğer riskleri, cilt riskleri, kas ve iskelet sistemi riskleri ve psikososyal risklerin oluşabileceği gözlemlenmiştir.

İş sağlı̆̆ı ve güvenliği; çalışanların iş emniyetini, sağlı̆̆ını ve rahatlığını sağlayan hukuk ve buna bağlı politika, süreç ve prosedürleri içeren multidisipliner bir organizasyon alanıdır. Diğer bir deyişle işyerlerinde faaliyet gösterilirken çeşitli sebeplerden ötürü çalışan sağlığı için tehdit oluşturabilecek unsurlara karşı tedbir amacıyla gerçekleştirilen sistematik ve bilimsel uygulamalar bütünüdür (Öktem, 2017).

Meslek hastalıkları ise çalışanın yaptığı işe bağlı olarak ortaya çıkan, hastalık yapıcı etkenlerin rol oynadığı ve büyük ölçüde önlenebilir olan sağlık problemleridir. İşverenlerin asli sorumlulukları arasında çalışanların genel sağlık durumlarının iyi olmasını sağlamanın yanı sıra meslek hastalıklarının ortaya çıkmasına engel olmak da bulunmaktadır. İş kaynaklı hastalık yapıcı etkenler uygun metotlarla kontrol altına alındığında meslek hastalıklarının oluşma riski minimize edilebilir. İşyerlerinde hastalıklara sebep olan bu unsurlar içerisinde; fiziksel, kimyasal ve biyolojik etkenler, tozlar, ergonomik ve psikososyal faktörler yer almaktadır (Vidinli vd.,2016).

Endüstrileşme ve modern anlamda teknolojilerin gelişmesi sonucunda meydana gelen sorunlardan birisi de ses kirliliğidir. Gürültü olarak da bilinen ses kirliliği, dinleyiciye anlamsız, istenmeyen gürültü ve insanları rahatsız eden düzensiz, yüksek ses olarak tanımlanır. Çalışma ve Sosyal Güvenlik Bakanlığı'na göre; Meslek hastalıklarının\% 10'u gürültüye bağlı işitme kaybı olarak tanımlanmaktadır. Gürültünün şiddeti, gürültüye maruz kalınan süre ve frekansı ile etkilenmenin sürekli ya da kesikli olması ve kişisel duyarlılık ile yaş, gürültüden etkilenme seviyesini doğrudan etkileyen en önemli unsurlardır.

$\mathrm{Bu}$ çalışmada çimento fabrikasındaki gürültü düzeylerinin ve çalışanlarının etkilenim seviyelerinin belirlenmesi ile alınacak önlemlerin tespit edilmesi amaçlanmıştır.

Bu amaca yönelik olarak çimento üretim sektöründe çeşitli ünite ve proseslerde çalışan personelin İş Sağlığ 1 ve Güvenliği (İSG) kapsamında maruz kaldığ1 gürültü düzeyleri ve maruziyetlerin yasal limitlerle karşılaştırılarak değerlendirmeleri yapilmıştır.

\section{Ses ve Gürültü}

Ses nesnel (fiziksel) ve öznel (fizyolojik) olmak kaydı ile iki farklı açılardan tanımlanmaktadır. Fiziksel açıdan gürültü, esnek bir ortamda (katı, sıvı, gaz) basınç dalgalanmaları veya titreşim kaynaklarının neden olduğu ortam parçalarının yer değiştirmesidir. Fizyolojik olarak gürültü, duyu organlarının elastik bir ortamda titreşim kaynağının neden olduğu basınç değişiklikleri kavramıdır (Hansen, 2001, Barron, 2003, Özgüven, 1986).

Sesin birimi desibeldir ve bir büyüklüğün, belirlenen referans değerine oranlanması ve bu oranın logaritmasının alınması ile elde edilen değer Graham Bell'in anısına Bel (B) olarak tanımlanmaktadır. Desibel (dB), elde edilen değerin 1/10 una karşılık gelmektedir. Herhangi bir işitme kaybı bulunmayan sağlıklı bir insan, $20 \mu \mathrm{Pa}$ ile $200 \mathrm{~Pa}$ arasında yeralan ses şiddetlerini duyabilmektedir. Sesin $20 \mu \mathrm{Pa}$ değerine işitme eşiği, $200 \mathrm{~Pa}$ değerine de ağrı eşiği adı verilir (Çınar, 2005).

Gürültü kelimesi ise Latin dilinde yüksek ses, beklenmeyen ve hoş olmayan sesler anlamına gelmekte olan "nausea" sözcüğünden türetilmiştir (Singh ve Davar, 2004). Duyulduğu zaman müzik sesi gibi beğeni sağlamayan ses olarak adlandırılmaktadır. Gürültüye neden olan sesde bütün sesler gibi hava basıncı altında ve üst kısmında belirli değişiklikler meydana getiren belirli bir titreşim ile meydana gelmektedir. Havadaki basınçta meydana gelen değişiklikler, kulağa dalgalar şeklinde gelmekte ve buna bağlı olarak ses şeklinde işitilebilmektedir (Çınar, 2005).

Gürültü, temel insan faaliyetleri, ulaştırma, sanayi gelişimi ve kalkınmanın sonucunda meydana gelmiştir. Kentsel nüfus gürültü kirliliğinden büyük ölçüde etkilenmektedir, ancak gürültü kirliliğinin etkileri, yan yollardaki küçük olan köylerde ve kasabalarda da oluşmaktadır. Gürültünün etkileri neredeyse evrensel olmakla birlikte, gelişimini tamamlamış olan devletler bile bu problemin farkına varamamışlardır.

Gürültü ve sesin ölçümünün yapılması oldukça geniş bir konu olmasının yanı sıra apayrı bir tekniktir. Ses türleri, spektral formlar, süreye bağlı olan değişkenler ve diğer birçok unsurla birlikte, gürültü ve ölçülmesi planlanan seslerin özelliği büyük ölçüde değişebilir. Bu nedenle ölçüm için kullanılan ekipman koşullara ve amaca göre seçilmezse yanlış veya yanıltıcı sonuçlar elde etmek mümkündür (Özey, 2014).

\section{Gürültünün Sınıflandırılması}

Gürültü frekansına ve zaman değişimine göre iki grupta incelenmektedir (Özey, 2014).

\section{Frekansına göre;}

Geniş bant gürültüsü; Gürültüye neden olan saf seslerin frekansları da oldukça geniş aralıkları kapsamaktadır. Gürültüye neden olan ses frekanslarının, bütün frekans aralığınca oluşmasına "Geniş Bant Gürültüsü” denilmektedir. Her frekans düzeyinde katkıların aynı olduğu gürültülere ise "Beyaz Gürültü” denilmektedir. Makinelerden kaynaklı gürültü geniş bant gürültüsüne örnek verilebilir.

Dar bant gürültüsü; Geniş bant gürültülerinin tam tersine, bu şekilde gürültülerin frekanslarının dağılımı, belirli düzeyde frekans bandında toplanmış grafik göstermektedir. Farklı bir anlatım ile gürültüyü meydana getiren temel seslerden frekansları belirli aralıklarda toplanmış olanlar baskın durumdadir. 


\section{Zaman değişimine göre;}

Kararlı gürültü; Genel olarak belirli bir zaman içerisinde değişimleri $5 \mathrm{~dB}(\mathrm{~A})$ içerisinde kalan gürültü, Yani gürültünün seviyesinde zamanla bir değişme gözlenmez.

Kararsız gürültü; Ses seviyeleri zamanla önemli oranda değişimler göstermektedir.

-Dalgalı gürültü, gürültü seviyelerinde önemli oranda değişikliklerin olduğu gürültüdür.

-Kesikli gürültü, bir gözlem sırasında ortam gürültüsündeki ani düşüştür ve ortam gürültüsü seviyesinin bir saniye veya daha fazla sürede devam eden değişim göstermeyen gürültü türüdür, durup tekrardan çalışmakta olan vantilatörlerin sesi gibi.

-Darbe gürültüleri, bir saniyeyi geçmeyen ya da vuruşların oluşturduğu gürültü türüdür.

\section{Gürültünün İnsan Sağlığı Üzerindeki Etkileri}

Meslek hastalığı listesi içerisinde iş sağlığ1 ve güvenliği kapsamında yer alan hastalıklar 5 grupta toplanmıştır;

1) Kimyasal maddelere bağlı şekilde ortaya çıkan hastalıklar

2) Mesleğe bağlı cilt hastalığ1

3) Pnömokonyozlar ve farklı solunum yolu hastalığı

4) Mesleki yönden bulaşıcı hastalıklar

5) Fiziki etkenlere bağlı olarak ortaya çıkan hastalıklar.

Sanayide gürültünün neden olduğu işitme kayıpları da fiziki etmenlere bağlı olarak meydana gelen meslek hastalığ ${ }_{1}$ şeklinde nitelendirilmektedir (Hisam, 2018).

Gürültünün insan sağlığı üzerindeki etkisinde etkilenme süreleri son derece önemli bir faktördür. Gürültüye maruz kalmanın insanlar arasında farklı sonuçları vardır. İç kulakta ki durum, önceki hastalıkları ve bireylerin hassasiyeti önemli durumlardir.

Gürültünün sağlık yönünden değerlendirilmesinde yaş unsuru da oldukça önemlidir. Kişilerdeki görme kayıpları gibi işitme kayıpları da 40 yaşında başlamaktadır. Bu nedenle, işitme kaybı hesaplaması 40 yıl ile sinırlıdır ve her y1l odyogramdan sonra 0,5 dB yaşa bağlı işitme kaybı düşülür (Hisam, 2018).

ÇSGB (Çalışma ve Sosyal Güvenlik Bakanlığı) tarafindan 28.07.2013 tarih ve 28721 sayılı Resmi Gazete'de yayınlanmış olan "Çalışanların Gürültü ile İlgili Risklerden Korunmalarına Dair Yönetmelik" İşçileri sağlık ve güvenlik tehlikelerinden, özellikle gürültüye maruz kalmadan kaynaklanan işitme kaybından korumaya yönelik minimum gereksinimler tanımlanmıştır. Bunlar:

a) En düşük maruziyet eylem düzeyi (LEX, 8saat) $=80$ $\mathrm{dB}(\mathrm{A})$ veya $($ Ptepe $)=112 \mathrm{~Pa}[135 \mathrm{~dB}(\mathrm{C})$ re. $20 \mu \mathrm{Pa}](20 \mu \mathrm{Pa}$ ölçüm aralığında $135 \mathrm{~dB}$ (C) şeklinde hesaplanmış olan değerler).

b) En yüksek maruziyet eylem düzeyi: (LEX, 8saat) $=85$ $\mathrm{dB}(\mathrm{A})$ ya da $($ Ptepe $)=140 \mathrm{~Pa}[137 \mathrm{~dB}(\mathrm{C})$ re. $20 \mu \mathrm{Pa}]$.

c) Maruziyet sınır değeri: (LEX, 8saat) $=87 \mathrm{~dB}(\mathrm{~A})$ veya (Ptepe) $=200 \quad \mathrm{~Pa}\left[\begin{array}{lllll}140 & \mathrm{~dB}(\mathrm{C}) & \text { re. } & 20 & \mu \mathrm{Pa}\end{array}\right]$ şeklinde yönetmeliklerde tespiti yapılmıştır (ÇSGB, 2013).

\section{Materyal ve Metot}

Çalışmanın konusunu oluşturan işletme çimento üretimi yapan bir tesistir. Fabrikada üretim faaliyetleri, hammaddelerin kırıcılar ile belli boyutlarda kırılmasını sağlayan üniteler, malzemenin homojene olmasını sağlayan homojenizasyon üniteleri, klinker üretim üniteleri, çimento üretim üniteleri ve paketleme üniteleri ile gerçekleştirilmektedir.

\section{1. İşletmede Üretim}

İşletmede klinker ve çimento üretimi hammadde ocaklarında patlatmalar sonucunda 1-1,5 m3 hacminde malzemeler ocaktan kamyonlar vasıtasıyla kırıcılara getirilmekte ve kırıcı bunkerlerine dökülmektedir. Burada, kalker, kil ile alçı taş1, boyutu 0-100 mm ebatlarına ulaşana kadar boyut küçültme işlemine tabi tutulur. Hammadde ocaklarından taşınan malzemelerin bir kısmı hammadde ocaklarında stoklanırken bir kısmı da hammadde kırma ünitelerinde ihtiyaç durumuna göre çekiçli kırıcı ile kırılmaktadır. Kalker ve kil kırıcılarından çıkan kırılmış malzeme, tamamen kapalı konveyör bantlar vasıtasıyla ön stoklama tesisine sevk edilmektedir.

Farklı tane boyutundaki ve farklı kimyasal özelliklerde ki hammaddeler kırıcı besleme bunkerlerine gönderilmektedir, kırılma işlemleri sırasında iyi derecede karışarak homojen bir yapıya dönüşmektedir, karıştırılabilecek boyutlara küçültülerek öğütme işlemine hazır olurlar.

Kırılan hammaddeler, farklı şekillerde yapı göstermemesi için ön homojene stok sahalarına beslenmektedir. Lineer stokhollerde ise alçı taşı, demir cevheri, katkı kalker, kum gibi katkı malzemeleri bulunmaktadır. Stokhollere malzemeler yığıcı ile stoklanır. Stoklanan malzemeyi sisteme besleyen ekipman ise kazıyıcıdır.

Ön homojenizasyonunu tamamlanmış olan hammaddeler, pişirme işlemine alınmadan önce ögütülmesi gerekmektedir. Öğütmenin amacı, hammadde karışımını farin olarak adlandırılan un gibi toz şekline getirerek kimyasal reaksiyon yüzey alanını arttırmaktır. Stokhollerde bulunan malzemeler farin değirmeni bunkerlerine aktarılır. Kireçtaşı, kil, demir cevheri, v.b. gibi kimyasal kompozisyona sahip malzemeler öğütülerek ince bir toz haline getirilir.

Farin değirmenlerinde öğütme ve kurutma işlemleri gerçekleştirilmektedir. Kurutma işlemi için döner fırından alınan atık sıcak gaz kullanılmaktadır. Değirmene yaklaşık \% 10-12 nemli olarak giren hammadde karışımı, fırından gelen ve değirmen girişinde yaklaşık $350{ }^{\circ} \mathrm{C}$ olan sıcak atık gaz ile kurutulur. Değirmenlerde öğütülen malzeme farin silolarına gönderilir.

Ön 1sıtıcı aşamasında kalsinasyonu büyük ölçüde tamamlanan farin döner firına intikal eder. Farin silosundan tartılarak alınmış olan farin siklonlardan meydana gelen bir ön 1sitıcı ile birlikte kuleye beslenmektedir. Siklonlardan aşağ inerken farin $300 C$ 'den 1000 oC'ye ulaşıncaya dek 1sıtılmakta $\% 90$ düzeyinde kalsine olmaktadır. Farin, fırında pişmesi esnasında hammadde içinde yer alan oksitler, ilk olarak serbest hale gelmekte daha sonra artan 1sı ile birlikte yeni bileşikler oluşturmaktadırlar. Ön 1sıtıcılardan gelen farin döner fırın içerisinde $1500 \mathrm{oC}$ 'de pişirilip kalsine edilmeleri için granüle hale getirilmektedir ve bu işlemler düşey değirmenlerde ya da bilyalı olan değirmenlerde gerçekleşmektedir. Fırın içerisinde sinterleşme meydana gelir ve yaklaşık $1300-1400^{\circ} \mathrm{C}$ ' de pişme 
prosesi gerçekleşir. Bu kısımda oluşan klinkerleşme tepkimeleri sonucunda meydana çıkan malzeme klinker soğutma ünitesine dökülür ve hava kullanılarak soğutulur. Elde edilen klinker stok sahasına sevk edilir. Fırında yakıt olarak kullanılan kömür, kömür besleme bunkerleri vasıtası ile kömür değirmenine sevk edilir ve öğütüldükten sonra döner firında yakıt olarak kullanılır.

Çimentonun üretiminde; klinker ve alçı taşına gereksinim duyulmaktadır. $\mathrm{Bu}$ malzemelere ek olarak katkılar şeklinde sınıflara ayrılan tras, marn, kalker, curuf, yüksek firın curufu da üretilecek olan çimento tipine göre katılır. Belirli düzeyde alçı taşı katılarak öğütülen klinkere portland çimentosu denilmektedir.

Alçıtaşı ve katkı şeklinde kullanılacak olan hammaddeleri çimento değirmenlerinde öğütülemeyecek düzeyde büyük parçalardan oluştuğu için, ilk olarak kırıcılardan geçirilmektedir. Değirmen çıkışından alınan numunenin incelik analizine göre seperatör yardımıyla tekrar ögütülür veya çimento tipine göre ayrı ayrı silolara nakledilerek stoklanır.

Silolardan alınan çimento havalı bant yardımıyla paketleme ünitesine sevk edilir. Paketleme makinaları döner kantarları sayesinde istenilen ağırlıkta $(25 \mathrm{~kg}, 50 \mathrm{~kg})$ üretimi gerçekleştirir. Üretilen torbalı çimento lastik bant vasıtasıyla nakliye araçlarına sevk edilir ve satışı yapılır. Silolardan direk olarak silobazlara dökme çimento yükleme yapılarak da satış gerçekleştirilmektedir.

\section{2. Ölçüm Yöntemi ve Cihazlar}

İşletmede oluşan gürültü düzeyi ölçümleri TS 2607 ISO 1999:2005 “Akustik - İş Yerinde Maruz Kalınan Gürültünün Tayini ve $\mathrm{Bu}$ Gürültünün Sebep Olduğu İşitme Kaybının Tahmini", ve TS EN ISO 11204 “Akustik - Makina Ve Donanımdan Yayılan Gürültü - Bir İş İstasyonundaki Ve Benzer Çevresel Düzeltmeler Uygulanmış Belirtilen Diğer Konumlardaki Emisyon Ses Basınç Seviyelerinin Tayini” standartları kullanılarak yapılmıştır. Saha çalışmaları;

Yönetim planının oluşturulması

Makinaların sayısı ve işletmedeki yerleşim durumlarının tespiti,

İş yerindeki personel sayısı/ vardiya sayıları / personellerin çalışma zamanının tespiti,

İşletme bölümlerinde bulunan makineler hakkında bilgi,

Personellerin sağlık durumları, işitme ile ilgili problemi olanların tespiti,

Varsa daha önce yapılmış ölçüm raporları incelenmesi,

Sahada ölçüm yapılacak noktalar, ölçüm metotları, ölçüm sürelerinin belirlenmesi şeklinde gerçekleştirilmiştir.

Ortam gürültü ölçümlerinde Tip 1 özellikte Svantek marka gürültü ölçüm cihazı, kişisel gürültü maruziyet ölçümlerinde ise Svantek marka dozimetre cihazları kullanılmıştır.

Saha ölçümleri sonucunda elde edilen bulgular öncelikle yasal limitlerle karşılaştırılmıştır. Söz konusu sonuçlar çalışanların bulunduğu ortama, çalışma geçmişine, görev aldığ 1 ünite ve proseslere göre değerlendirilmiştir.

\section{Araştırma Sonuçları ve Tartışma}

İşletmede gürültü maruziyeti ölçümleri TS 2607 ISO 1999 (2005) standardı ortam gürültü ölçümleri ise TS EN ISO 11204 standardı kullanılarak yapılmıştır. Ölçümler hızlı zaman ağırlıklı e-ISSN: 2148-2683 modda Eşdeğer ses düzeyi (Leq), gürültü maruziyet düzeyi (LEX8h), en yüksek ses basınç düzeyi (Ptepe) değerlerini kapsamaktadır.

En yüksek ses basıncı (Ptepe): Bir ölçüm aralığındaki en yüksek anlık ses basıncıdır. C veya $Z$ frekansında ölçülmektedir.

Hızlı zaman ağırlıklandırma, F: Gürültü ölçüm cihazlarında zaman sabitleri $125 \mathrm{~ms}$ ve $1000 \mathrm{~ms}$ olan hılı (F) ve yavaş (S) zaman modlarını bulundurmaktadır. Hizlı modda yapılan ölçümler 125 ms'lik aralıklarla kaydedilmektedir.

Eşdeğer ses düzeyi, Leq, LAeq: Belirli bir süredeki toplam ses enerjisi eşdeğer ses basınç seviyesine karşılık gelmekte olup birimi dB'dir.

Günlük gürültü maruziyet düzeyi (LEX,8saat): TS 2607 ISO 1999 (2005) standardında tanımlandığı gibi en yüksek ses basıncının ve anlık darbeli gürültünün de dâhil olduğu Aağırlıklı bütün gürültü maruziyet düzeylerinin, sekiz saatlik bir iş günü için zaman ağırlıklı ortalamasıdır.

İşletmede gürültü maruziyet ölçümleri ve ortam ölçümleri kırıcılar (2 adet), farin değirmeni (2 adet), döner firın (2 adet), çimento değirmeni (2 adet), kömür değirmeni (2 adet), paketleme ünitesi (1 adet) olmak üzere toplam 6 bölüm 11 ünitede toplam 33 ölçüm gerçekleştirilmiştir. Ortam ölçümleri bölüm bazında yapılmış olup 6 ölçüm gerçekleştirilmiştir.

Kömür değirmenine ait 1/3 oktav bandında her bir frekans bandı için ortam gürültü düzeyi Leq=83,1 $\mathrm{dB}(\mathrm{A})$ olarak ölçülmüştür.

ÇSGB (Çalışma ve Sosyal Güvenlik Bakanlığı) tarafından 28.07.2013 tarih ve 28721 sayılı Resmi Gazete'de yayınlanmış olan "Çalışanların Gürültü ile İlgili Risklerden Korunmalarına Dair Yönetmelik" de En yüksek maruziyet eylem düzeyi: (LEX, 8 saat $)=85 \mathrm{~dB}(\mathrm{~A})$ ya da $($ Ptepe $)=140 \mathrm{~Pa}[137 \mathrm{~dB}(\mathrm{C})$ re. 20 $\mu \mathrm{Pa}$. belirtilmektedir (ÇSGB, 2013).

Yönetmelikte kişisel maruziyet ölçüm değerleri belirtilmesine karşın ortam gürültü düzeyi ölçümünün yapıldığı kömür değirmenlerinde de bu sınır değerlerin dikkate alınması gürültü nedeni ile meydana gelebilecek olumsuz etkilerin azaltılmasına yönelik tedbirlerin alınması açısından önemlidir. Kömür değirmenlerinin yakınında bulunan çalışanların ya da kömür değirmenlerinin bulunduğu yerden geçiş yapacak çalışanların kişisel koruyucu donanımlarını takması ya da değirmen çevresinde izolasyon tedbirlerinin alınması gürültü etkilerinin azaltılması açısından yararlı olacaktır.

Çimento değirmenlerinde ortam gürültü düzeyi Leq $=75,8$ $\mathrm{dB}(\mathrm{A})$, paketleme ünitelerinde ortam gürültü düzeyi Leq $=70,7$ $\mathrm{dB}(\mathrm{A})$, farin değirmenlerinde ortam gürültü düzeyi Leq $=79,8$ $\mathrm{dB}(\mathrm{A})$ ve döner firın ünitelerinde ortam gürültü düzeyi Leq=78,3 $\mathrm{dB}(\mathrm{A})$ olarak ölçülmüştür.

Kırıcılara ait 1/3 oktav bandında her bir frekans bandı için ortam gürültü düzeyi Leq=92,1 $\mathrm{dB}(\mathrm{A})$ olarak ölçülmüş olup kırıcıların olduğu ortamda da uzun süre bulunulması işitme sağlığı açısından olumsuz etkiler getireceğinden kömür değirmenlerinde olduğu gibi yakınında bulunan çalışanların ya da kırıcıların bulunduğu yerden geçiş yapacak çalışanların kişisel koruyucu donanımlarını takması ya da kırıcılar çevresinde gürültü azaltımına yönelik izolasyon tedbirlerinin alınması önemlidir.

Gürültü maruziyet ölçümleri tam gün ölçüm stratejisi ile her bir ünitede 3 kişi üzerine gürültüye maruz kalan kulağın iç kulak 
kanalının girişinin 0,1 metre uzağına omuz başına gelecek şekilde ve omuzun yaklaşık olarak 0,04 metre hizasında dozimetreler takılarak 8 saatlik tam gün ölçümler yapılmış olup toplam 33 ölçüm gerçekleştirilmiştir.

Tablo 1. de kırıcılar, farin değirmenleri, çimento değirmenleri, kömür değirmenleri, döner fırınlar ve paketleme ünitesinde yapılan 8 saatlik ölçümler verilmiştir.

Balc1 (2016), çimento üretim sektöründe gürültü düzeylerinin belirlenmesine yönelik 3 işletmede yaptığ1 çalışmada kırıcı, farin değirmenleri ve çimento değirmenlerinde yüksek gürültü maruziyetinin olduğunu, kırıcı ve çimento değirmeninde en yüksek maruziyet eylem değerinin aşıldığını, farin değirmenlerinde ise sınır değerlere yakın veya aştığını belirtmiştir.

İlgürel ve Sözen (2005), yaptıkları çalışmada gürültünün endüstrileşme ve şehirleşme ile beraber pek çok ülkede insan sağlığını ve hayat kalitesini etkilediğinden bu durumun ciddi bir çevre sorunu haline geldiğini belirtmişlerdir. Sanayide birbirinden farklı gürültü düzeylerine sahip mekanlarda çalışan kişilerin gürültü düzeylerinden etkilenme süreçlerini inceleyen bu çalışmada, gürültü düzeylerine ait ölçümler ve anket çalışmaları yapılarak toplanan veriler değerlendirilmiş ve gürültü seviyeleri ile çalışanların maruz oldukları gürültü seviyelerinden etkilenme durumları arasındaki ilişkileri ortaya konulmuştur.

Topçu (2016), çimento üretim sektöründe risk değerlendirmesi yaptığı çalışmada dokuz ana üretim bölümünde gürültü maruziyeti kaynaklı riskler arasında en yüksek puanlıların konkasör ünitesi olduğu, bu üniteyi sırasıyla çimento değirmeni, döner firın ve farin değirmeninin takip ettiğini belirtmiştir.

Tokdemir (2019), çimento fabrikasında gürültünün belirlenmesine yönelik yaptığı çalışmada, çimento değirmeni, paketleme ünitesi, farin değirmeni, kömür değirmeni ve kırıcı da ölçümler gerçekleştirmiştir. Elde edilen ölçümlerin değerlendirilmesinde farklı ünitelere ait ölçüm sonuçlarının yönetmelikte belirtilen sınır değerleri aşmadığı belirtilmiştir.

$\mathrm{Bu}$ çalışmada da işletmede yapılan ölçümler, Çalışma ve Sosyal Güvenlik Bakanlığ tarafindan 20/6/2012 tarih ve 6331 sayılı İş Sağlığı ve Güvenliği Kanunu ve bu kanuna istinaden çıkarılan "Çalışanların Gürültü İle İlgili Risklerden Korunmalarına Dair Yönetmelik" Madde 5 e göre "En Yüksek Maruziyet Eylem Değeri" olan 85 dBA veya Ptepe=137 dBC'ye göre değerlendirilmiştir. Bu kapsamda kırıc1 1, kırıc1 2, kömür 1, kömür 2 ve döner fırın 1 ünitelerine ölçüm değerlerinin en yüksek maruziyet eylem değerini aştığı belirlenmiştir.

Çoşgun vd. (2008), Şehirleşmenin, sanayileşmenin ve teknolojinin gelişmesi ile birlikte gürültünün önemli bir çevre ve sağlık sorunu haline geldiğini, gürültü maruziyetinden etkilenme sonucu insanların psikolojik, ruhsal ve fiziksel sağlıklarının bozulduğunu belirtmişlerdir. Gürültünün önlenmesi ve azaltılmasına yönelik bazı tedbirlerin tasarım aşamasında alınması gerektiğini vurgulamışlardır. Yapılan bu çalışmada bir yapının iç mekanındaki gürültü oluşturan kaynakların neden olduğu gürültü düzeylerinin belirlenmesi, ölçüm sonuçlarının değerlendirilmesi ve çözüm önerileri sunulmuştur.

Aynı üretim sektöründe Balcı (2016) ve Topçu (2016)' nın yaptığı çalışmalarda sınır değerlerin aşıldığı belirtilen üniteler ile bu çalışmada sınır değerlerin aşıldığı üniteler benzerlik göstermektedir. Gürültü kaynaklarından özellikle kırma ve ögütme faaliyetinin yapıldığı kırıcı ile değirmenlerin gürültü düzeylerinin yüksek olduğu tespit edilmiştir.

Arslan (2017), çimento sektöründe faaliyet gösteren fabrikalarda farin değirmenleri, çimento değirmenleri, firın manto soğutucu fanlar gibi gürültü kaynaklarında gürültü düzeyini azaltmak için mücadele programı uygulanması gerektiğini belirtmiştir. Gürültünün kaynağında önlenmesini, iş ekipmanlarının düzenli olarak bakım ve onarımlarının yapılmasını ve gürültünün yayılımının engellenmesinin önemini belirterek bu önlemlerle gürültü düzeyinin azaltılamaması durumunda çalışanlar üzerindeki etkisini azaltmak için kişisel koruyucu donanımların kullanılmasının gerekliliğini vurgulamıştır.

$\mathrm{Bu}$ çalışmada da sınır değerlerini aşan ünitelerde oluşan gürültünün yayılımını önlemek için gürültü emici malzemelerin ve engelleyici bariyerlerin kullanılması gürültü maruziyet değerlerinin azaltılmasına neden olacaktır. Aynı zamanda idari tedbir olarak maruziyet zamanının azaltılması, dinlenme ve çalışma süreleri ile ilgili düzenlemelerin yapılması çalışan sağlığı açısından yararlı olacaktır.

Gengeç (2005), Çalışmasında İSG kapsamında geçmişten günümüze kadar olan süreçleri değerlendirmiş, hava kirliliği ve gürültü kirliliğini ele alarak, yapılan ölçümlerin değerlendirilmesiyle elde edilen sonuçlar doğrultusunda kişisel koruyucu ve ekipmanlar önermiştir.

Güvercin ve Aybek (2016), Yaptıkları çalışmada, iş sağlığ ve güvenliği bakımından özellikle iki adet problemle karşılaştıklarını, bu problemleride hava ve gürültü kirliliği olarak sıralamışlardır. Gürültünün çalışanlar üzerinde geçici ya da sürekli olarak işitme fonksiyonlarında kayıplara sebep olabildiğini aynı zamanda insanların sağlıklarını fizyolojik ya da psikolojik açıdan bozabileceklerini belirtmişlerdir. $\mathrm{Bu}$ araştırmada gürültü düzeyleri tespit edilerek elde edilen sonuçlar, ilgili yönetmelikler çerçevesinde değerlendirilmiş ve söz konusu işletmelerde gürültünün olumsuz etkilerinin azaltılmasına yönelik öneriler sıralanmıştır.

Rençber (2019), yaptığı çalışmada iş sağlığı ve güvenliği kapsamında eğitimlerin verilmesinin, kişisel koruyucu donanımların işveren tarafında temin edilmesinin yanı sıra çalışanların iş yeri hekimi, iş güvenliği uzmanı, ustabaşı tarafından denetlemesinin gerekliliği vurgulanmıştır.

İşletmede çalışanların kişisel gürültü maruziyetini indirgemek için kulak koruyucu donanımların kullanması özellikle sınır değerleri aşan ünitelerde mutlaka gerekli olup, Rençber (2019)'un çalışmasında belirttiği gibi kullanım ile ilgili eğitim, denetim ve kulak koruyucuların etkinliğinin kontrol edilmesi işlemleri iş sağlığ ve güvenliği uzmanı ile iş yeri hekimi tarafından yapılmaktadır. 
Tablo 1. Ünitelere ait Lex 8 h ölçüm değerleri.

\begin{tabular}{|c|c|c|c|c|c|c|}
\hline \multicolumn{3}{|c|}{ Ölçüm Bilgileri } & \multicolumn{4}{|c|}{ Ölçüm Sonuçları } \\
\hline No & $\begin{array}{l}\text { Ölçüm } \\
\text { Süresi } \\
(\mathrm{dk})\end{array}$ & Bölüm & $\begin{array}{l}\text { Lp,A,eqTn } \\
\text { dB (A) }\end{array}$ & $\begin{array}{l}\mathrm{L}_{\mathrm{EX}} 8 \mathrm{~h} \\
\mathrm{~dB}(\mathrm{~A})\end{array}$ & $\begin{array}{l}\text { Ptepe } \\
\text { dB (C) }\end{array}$ & $\begin{array}{c}\text { En Yüksek } \\
\text { Maruziyet Sınır } \\
\text { Değeri } \\
\end{array}$ \\
\hline \multirow{3}{*}{1} & \multirow{3}{*}{480} & \multirow{3}{*}{ Kırıcı 1} & 93 & \multirow{3}{*}{$92,3 \pm 3$} & \multirow{3}{*}{141,3} & \multirow{3}{*}{$\begin{array}{c}\mathrm{dB}(\mathrm{A}) \leq 85 \\
\mathrm{~dB}(\mathrm{C}) \leq 137\end{array}$} \\
\hline & & & 92,6 & & & \\
\hline & & & 93,1 & & & \\
\hline \multirow{3}{*}{2} & \multirow{3}{*}{480} & \multirow{3}{*}{ Kırıc1 2} & 89,7 & \multirow{3}{*}{$89,8 \pm 3,1$} & \multirow{3}{*}{138,7} & \multirow{3}{*}{$\begin{array}{c}\mathrm{dB}(\mathrm{A}) \leq 85 \\
\mathrm{~dB}(\mathrm{C}) \leq 137\end{array}$} \\
\hline & & & 90,6 & & & \\
\hline & & & 89,8 & & & \\
\hline \multirow{3}{*}{3} & \multirow{3}{*}{480} & \multirow{3}{*}{$\begin{array}{c}\text { Farin Değirmeni } \\
1\end{array}$} & 78,5 & \multirow{3}{*}{$77,2 \pm 4,4$} & \multirow{3}{*}{122,3} & \multirow{3}{*}{$\begin{array}{c}\mathrm{dB}(\mathrm{A}) \leq 85 \\
\mathrm{~dB}(\mathrm{C}) \leq 137\end{array}$} \\
\hline & & & 76,2 & & & \\
\hline & & & 77,4 & & & \\
\hline \multirow{3}{*}{4} & \multirow{3}{*}{480} & \multirow{3}{*}{$\begin{array}{c}\text { Farin Değirmeni } \\
2\end{array}$} & 76,7 & \multirow{3}{*}{$77,9 \pm 4,7$} & \multirow{3}{*}{124,2} & \multirow{3}{*}{$\begin{array}{c}\mathrm{dB}(\mathrm{A}) \leq 85 \\
\mathrm{~dB}(\mathrm{C}) \leq 137\end{array}$} \\
\hline & & & 78,1 & & & \\
\hline & & & 78,4 & & & \\
\hline \multirow{3}{*}{5} & \multirow{3}{*}{480} & & 81,2 & & & $\mathrm{~dB}(\mathrm{~A}) \leq 85$ \\
\hline & & $\begin{array}{l}\text { Çimento } \\
\text { Değirmeni } 1\end{array}$ & 83 & $82,2 \pm 4,1$ & 127,7 & $\mathrm{~dB}$ \\
\hline & & & 83,1 & & & \\
\hline & & & 82,2 & & & $\mathrm{~dB}(\mathrm{~A}) \leq 85$ \\
\hline 6 & 480 & Değirmeni 2 & 81,8 & $81,5 \pm 3,1$ & 126,3 & $<137$ \\
\hline & & & 81,4 & & & \\
\hline & & & 87,8 & & & $\mathrm{~dB}(\mathrm{~A}) \leq 85$ \\
\hline 7 & 480 & Döner Fırın 1 & 89,4 & $88,5 \pm 3,6$ & 136,3 & $\mathrm{~dB}(\mathrm{C})<137$ \\
\hline & & & 89 & & & \\
\hline & & & 81,2 & & & $\mathrm{~dB}(\mathrm{~A}) \leq 85$ \\
\hline 8 & 480 & Döner Fırın 2 & 79,6 & $79,9 \pm 3,9$ & 131,7 & $\mathrm{~dB}(\mathrm{C}) \leq 137$ \\
\hline & & & 79,4 & & & \\
\hline & & Kömür & 87,8 & & & $\mathrm{~dB}(\mathrm{~A}) \leq 85$ \\
\hline 9 & 480 & Deŏirmeni 1 & 88,9 & $88,5 \pm 3,5$ & 140,2 & $\mathrm{~dB}(\mathrm{C})<137$ \\
\hline & & & 89,4 & & & \\
\hline & & & 94,3 & & & $\mathrm{~dB}(\mathrm{~A}) \leq 85$ \\
\hline 10 & 480 & Deŏirmeni 2 & 92,6 & $93,4 \pm 3,8$ & 144,1 & $\mathrm{~dB}(\mathrm{C})<137$ \\
\hline & & & 94,1 & & & \\
\hline & & & 69,6 & & & $\mathrm{~dB}(\mathrm{~A}) \leq 85$ \\
\hline 11 & 480 & Ünitesi & 71,2 & $70,2 \pm 3,5$ & 115,6 & $\mathrm{~dB}(\mathrm{C}) \leq 137$ \\
\hline & & & 70,5 & & & \\
\hline
\end{tabular}

\section{Sonuç}

6 adet bölümde yapılan ortam gürültü ölçümlerinde kömür değirmenlerinin olduğu bölümde $83,1 \mathrm{~dB}(\mathrm{~A})$, çimento değirmenlerinin olduğu bölümde $75,8 \mathrm{~dB}(\mathrm{~A})$, paketleme ünitesinin olduğu bölümde $70,7 \mathrm{~dB}(\mathrm{~A})$, farin değirmenlerinin olduğu bölümde 79,8 $\mathrm{dB}(\mathrm{A})$, döner firınların olduğu bölümde $78,3 \mathrm{~dB}(\mathrm{~A})$ ve kırıcıların olduğu bölümde $92,1 \mathrm{~dB}(\mathrm{~A})$ değerleri elde edilmiştir.

Günlük gürültü maruziyet değerlerinin en çok kırıc1 1, kırıc1 2, kömür 1, kömür 2 ve döner firın 1 ünitelerinde olduğu tespit edilmiştir. Ortam gürültü düzeylerinin ise özellikle kömür e-ISSN: 2148-2683 değirmenlerinin ve kırıcı ünitelerinin bulunduğu yerlerde yüksek olduğu tespit edilmiş̧ir.

Ortam gürültüsünün yüksek düzeyde olduğu ünite alanlarından geçiş yapacakların kişisel koruyucu donanımlarını takması ya da değirmen ve kırıcı çevresinde izolasyon tedbirlerinin alınması gürültü maruziyetinin azaltılmasını sağlayacaktır.

Sınır değerlerini aşan ünitelerde oluşan gürültünün yayılımını önlemek için gürültü emici malzemelerin ve engelleyici bariyerlerin kullanılması gürültü maruziyetinin azaltılmasında etkili olacaktır. 
Fan ve basınçlı hava kompresörleri vb. kaynakların etraflarının uygun izolasyon malzemesi kullanarak kapatılması mevcut gürültünün yayılmasını engellemede etkili olacaktır.

Aynı zamanda idari tedbir olarak maruziyet zamanının azaltılması, dinlenme ve çalışma süreleri ile ilgili düzenlemelerin yapılması gerekmektedir.

Çalışanların kişisel gürültü maruziyetini indirgemek için kulak koruyucu donanımların kullanması işitme sağlığ açısından yararlı olacaktır aynı zamanda kişisel koruyucu ve donanımların kullanımı ile ilgili yapılan eğitim, denetim ve kulak koruyucuların etkinliğinin kontrol edilmesi işlemlerinin devamlılığının sağlanması önem arz etmektedir.

Tesiste kapasite artışı ya da yenilenme gibi durumlarda yapılacak yeni yatırımlarla herhangi bir ünitenin kurulması, makinaların yerleştirilmesi gibi çalışmalardan önce gürültü düzeyleri hesaba katılmalı ve kurulumlar elde edilen verilere göre yapılmalıdır.

Tesisin çalışma koşullarında herhangi bir değişikliğin olması durumunda mutlaka risk değerlendirme analizleri yapılmalı ve gürültü kaynaklarına ait ölçümler yenilenmelidir.

\section{Kaynakça}

Arslan, V., (2017). Konya Çimento Fabrikasında İş Sağlı̆̆ ve Güvenliği Uygulamaları. Uluslararası Maden İşletmelerinde İşçi Sağlığı ve İş Güvenliği Sempozyumu, Zonguldak, 02-03 Kasim, 758-773.

Balc1, S. (2016). Çimento Üretiminde Toz ve Gürültü Maruziyetinin Değerlendirilmesi. İş Sağlığı ve Güvenliği Uzmanlık Tezi, Çalışma ve Sosyal Güvenlik Bakanlığı İş Sağlığı ve Güvenliği Genel Müdürlüğü, Ankara, 83s.

Barron, R.F., (2003). Industrial Noise Control and Acoustic. Marcel Dekker Inc. 560p. New York.

Çınar, İ., (2005). Madencilikte Gürültü Analizi, Modellenmesi ve Haritalanması. Selçuk Üniversitesi Fen Bilimleri Enstitüsü, Doktora Tezi.

Çoşgun, T., Yükseli F.A., ve Çoşgun, A., (2008). Tünel Kalıpla İnşa Edilen Binalarda Yaşanan Gürültü Problemleri Üzerine Bir Araştıma. Uygulamalı Yer Bilimleri Dergisi, 1, 65-72.

ÇSGB, (2013). Çalışanların Gürültü ile İlgili Risklerden Korunmalarına Dair Yönetmelik. Çalışma ve Sosyal Güvenlik Bakanlığı, 6s, Ankara.

Gengeç, E., (2005). Işs Sağliğl ve $\dot{I}_{s ̧}$ Güvenliği Açısından Hava ve Gürültü Kirliliği. Yüksek Lisans Tezi, Kocaeli Üniversitesi Fen Bilimleri Enstitüsü, Kocaeli, 148s.

Güvercin, Ö., ve Aybek, A., (2003). Taş Kırma ve Eleme Tesislerinde Gürültü Sorunu. KSÜ Fen ve Mühendislik Dergisi, 6, (2), 101-107.

Hansen, C.H., (2001). Fundamentals of Acoustics, in Occupational Exposure to Noise: Evaluation, Prevention and Control, (Goelzer, B., Hansen, C.H., Sehrndt, G.A., Eds.) Publication Series from the Federal Institute for Occupational Safety and Health, Document published on behalf of the World Health Organization-Dortmund, pp.2352 , Berlin.
HİSAM, İş Sağllğg Ve Güvenliği Meslek Hastalıkları Uygulama Ve Araştırma Merkezi http:// www.hisam.hacettepe.edu.tr/ ismeslekhastaliklari/25GurultuveSaglikGBIK1-2.pdf, (Erişim tarihi: 10.02.2018).

İlgürel, N., ve Sözen, Ş.M., (2005). Değişik Sanayi Kuruluşlarında Gürültünün Nesnel, Öznel ve Yönetmelikler Bağlamında Incelenmesi. YTÜ Mimarlık Fakültesi Dergisi, 2005, 1,(1), 9-17

Öktem, R., (2017). İş Să̆ğğ ve Güvenliği Ders Notlart. http://comp.eng.ankara.edu.tr/files/2017/11/477-tr.pdf (Erişim tarihi: 12.04.2020).

Özey, R., (2014). Çevre Sorunları. Genişletilmiş 4. Baskı, Aktif Yayınevi, s. 302, İstanbul.

Özgüven, N., (1986). Endüstriyel Gürültü Kontrolu. TMMOB Makina Mühendisleri Odası Yayını, No.118, 178s. Ankara.

Rençber, Y.S., (2019). Bir Tekstil Fabrikasında Çalışan İşçilerin İs Sağlığl ve Güvenliği Konusundaki Bilgi Düzeyleri ve Sağllk Risklerinin Değerlendirilmesi. Doktora Tezi, Dicle Üniversitesi, Sağlık Bilimleri Enstitüsü, Diyarbakır, 231s.

Singh, N. ve Subhash C. Davar, (2004). Noise PollutionSources, Effects and Control. Journal of Human Ecology, 16(3), 181.

Sönmez, H., (2018). Çimento sektörü büyümeye devam ediyor. http://www.dunyainsaat.com.tr/haber/cimento-sektorubuyumeye-devam-ediyor/24258 (Erişim tarihi: 22.09.2020).

Tokdemir, M., (2019). Sivas Votorantim Çimento Fabrikasının Bölümlerinin Gürültü Açısından Değerlendirilmesi. Yüksek Lisans Tezi, Cumhuriyet Üniversitesi, Fen Bilimleri Enstitüsü, Sivas, 65s.

Topçu, D.S., (2016). Çimento Üretim Süreçlerindeki Işs Sağlı̆̆ ve Güvenliği Risklerinin Tespiti ve Çözüm Önerileri. İş Sağlığı ve Güvenliği Uzmanlık Tezi, Çalışma ve Sosyal Güvenlik Bakanlığı İş Sağlığı ve Güvenliği Genel Müdürlüğü, Ankara, 121s.

TS EN ISO-11204, (2012). Akustik - Makina Ve Donanımdan Yayılan Gürültü - Bir İş Istasyonundaki Ve Benzer Çevresel Düzeltmeler Uygulanmış Belirtilen Diğer Konumlardaki Emisyon Ses Basınç Seviyelerinin Tayini. Türk Standartları Enstitüsü, Ankara, 37s.

TS-2607 ISO 1999, (2005). Akustik - İş Yerinde Maruz Kalınan Gürültünün Tayini Ve Bu Gürültünün Sebep Olduğu Işitme Kaybının Tahmini. Türk Standartları Enstitüsü, Ankara, 26s.

Ünal, T., (2018). Çimento sektörü 2017 değerlendirmesi, 2018 Öngörüleri. http://www.yapimalzeme.com.tr/cimentosektoru-2017-degerlendirmesi-2018-ongoruleri-ceisyonetim-kurulu-baskani/ (Erişim tarihi: 22.09.2020).

Vidinli, N., Özkan, E. K., Topçu, A. D., Yağmurluklu, Y., Gedikli, F. G. ve Kürkçü, E. A., (2016). Çimento Sektöründe Tozla Mücadele Rehberi. Çalışma ve Sosyal Güvenlik Bakanlığı İş Sağlığı ve Güvenliği Genel Müdürlüğü, 47s. Ankara. 